\title{
Evaluation of surgical outcome of giant intracranial meningiomas
}

\author{
Ramy Teama*, Mohamed Adawy and Mohamed Emara
}

\begin{abstract}
Background: The surgery of giant intracranial meningiomas (GIM) is difficult due to its large size, prominent vascularity, including and limiting visualization of various neurovascular structures, and severe cerebral edema. In this study, we will evaluate the surgical outcome of giant meningiomas according to our experience at our hospital in management of giant intracranial meningioma.

Main body: A retrospective analysis of 48 patients with histologically proven meningioma ( $\geq 6-\mathrm{cm}$ diameter) who underwent surgical treatment at Benha University hospitals over a period of 5 years (June 2014/June 2019) is presented. Details regarding clinical presentation, imaging findings, surgical results and complications, and follow-up status were collected. The study group was composed of 41 females and 7 males. The age of the study group ranged from 38 to 69 years with an average of 49 years. The mean follow-up period was 36 months. Different approaches were used according to tumor location with the aim of gross total removal. Gross total removal was achieved in $90 \%$ of cases (43 cases). There were 2 cases with intraoperative complications not related to surgery. Recurrence was present in 4 cases. Mortality in this series was $4 \%$ ( 2 cases) with no reported intraoperative mortality.

Conclusion: Management of giant intracranial meningioma is a relatively common practice in neurosurgical centers in developing countries with the aim of radical total surgical removal being the first and most optimum option. Large size makes surgery difficult, but young age, meticulous surgical techniques, proper localization, trying to minimize operative time, and Simpson grade are of special value. Interdisciplinary cooperation is essential to avoid the common complications like pulmonary embolism (PE), postoperative hematoma in tumor bed that leads to bad surgical outcome.
\end{abstract}

Keywords: Meningioma, Giant, Skull base, Complication, Simpson grade

\section{Introduction}

Giant intracranial meningioma is defined as intracranial meningiomas with diameter larger than $6 \mathrm{~cm}$ [1]. Meningiomas arise from arachnoid cap cells; these tumors account for the second most frequent type of brain adult tumors representing $20 \%$ of all brain tumors [2-4]. The giant intracranial meningioma (GIM) represents specific type of brain tumors which include and surround the vital neurovascular structures making the usual regimen of treatment, surgery, a technically challenging treatment option [5].

\footnotetext{
* Correspondence: ramyteama82@gmail.com

Neurosurgery Department, Benha University, Benha, Egypt
}

Nowadays, different treatment regimens are used to deal with these tumors, including conservative treatment, subtotal removal, radiosurgery as primary or adjuvant therapy, and aggressive total surgical removal [6]. Despite different modes of treatment used for meningioma, surgery is the primary and main mode of treatment due to pressure manifestations and inclusion of the brain stem, cranial nerves, and brain vasculature [6]. The surgery of GIM is difficult due to its huge volume, high vascularity, included several neurovascular structures limiting its visualization, and marked brain edema [5]. Total surgical removal of giant skull base meningiomas is technically challenging and so hard due to its attachment and inclusion of the skull base vital
Springer Open (c) The Author(s). 2020 Open Access This article is licensed under a Creative Commons Attribution 4.0 International License, which permits use, sharing, adaptation, distribution and reproduction in any medium or format, as long as you give appropriate credit to the original author(s) and the source, provide a link to the Creative Commons licence, and indicate if changes were made. The images or other third party material in this article are included in the article's Creative Commons licence, unless indicated otherwise in a credit line to the material. If material is not included in the article's Creative Commons licence and your intended use is not permitted by statutory regulation or exceeds the permitted use, you will need to obtain permission directly from the copyright holder. To view a copy of this licence, visit http://creativecommons.org/licenses/by/4.0/. 
structures either vascular or neurological [6]. In this study, we will evaluate the surgical outcome of giant intracranial meningiomas according to our experience at our hospital.

\section{Patients and methods}

This is a retrospective study including 48 patients with giant intracranial meningioma $(\geq 6-\mathrm{cm}$ diameter) upon whom we performed surgical intervention at Benha University hospitals in a period of 5 years (from June 2014 to June 2019). The clinical and radiologic data was obtained from the department database including complete history, general examination, neurological examination, ophthalmologic evaluation, and neuroradiological studies. The tumors were divided into different histological groups according to the World Health Organization (WHO) classification.

Before surgical intervention, we performed routine contrast-enhanced brain MRI imaging; diagnostic magnetic resonance angiography (MRA) was done in some cases (parasagittal meningiomas). The follow-up schedule included computerized tomography (CT) on the brain or contrast-enhanced magnetic resonance imaging (MRI) 1 day postoperative, 3 months after surgery, and then every year.

In each case, we recorded the actual time of surgery, intraoperative blood loss, laboratory investigation results, adjuvant therapy, and complications. We revised carefully the Simpson grade, previously used radiotherapy, and the tumor location. We reviewed the medical sheet, operative sheet, radiological studies, and follow-up data of the cases. Cavitronic ultrasonic aspiration device (CUSA) was used in many cases whenever possible; neuronavigation gave us help in proper localization of flab to avoid too much flab enlargement in already large flab. Operating microscope type was used as well.

Various approaches were used with tumor location being the most important determining factor. Convexity meningioma was removed by convexity approach, olfactory groove meningioma was removed by bifrontal approach, sphenoid ridge meningioma was removed by pterional or cranio-orbitozygomatic (COZ) approaches, temporal floor meningioma was removed by zygomatic or $\mathrm{COZ}$ approach, petroclival meningiomas were removed by retrosigmoid approach; and the case of foramen magnum meningioma (laterally located) was operated using midline suboccipital approach.

\section{Results}

Forty-eight patients with giant intracranial meningioma were operated in the period between June 2014 and June 2019. The group was composed of the following lesions according to location of meningioma: 13 convexity meningioma, 3 parasagittal meningioma, 13 olfactory groove meningioma, 7 sphenoid ridge meningioma, 1 foramen magnum, 6 temporal meningioma, 2 tuberculum sellae, and 3 petroclival meningiomas (Figs. 1, 2, 3, 4, 5, and 6).

In this study, giant meningioma was defined as larger than $6 \mathrm{~cm}$ in at least one of the three dimensional planes with a mean diameter of $7.6 \mathrm{~cm}$.

The patients in this study group were composed of 41 females and 7 males. The age of patients in this series ranged from 38 to 69 years with a mean age of 49 years (Table 1 ). The follow-up period ranged from 6 to 60 months with a mean period of 36 months. The aim of surgery in this study was gross total removal, but the giant size of these tumors was an obstacle against total removal in some cases due to contained important neurovascular structure as a main cause.

Previous surgical removal was done in three cases (6\%). The results of surgery was as follows: Simpson grade I was performed in $20 \%$ of cases, Simpson grade II was performed in 55\% of cases, Simpson grade III was performed in $15 \%$ of cases, and Simpson grade IV was performed in $10 \%$ of cases (Table 2).

Stereotactic radiosurgery (SRS) is usually used for residual tumors after subtotal removal [7]. Postoperative radiosurgery in our series was used in 5 cases in which subtotal removal was the result (Simpson grade IV). The tumor size has been stabilized in three cases while increased size has occurred in 2 of these cases in spite of radiosurgery.

Recurrence of tumors in this study occurred in 4 cases $(2$ cases of Simpson grade IV and 2 cases of Simpson grade III); in two cases, we performed reoperation while one case refused surgery, and the last one was lost during follow-up. The recurrence rate reported in literature is $15 \%$ after total removal [8] and is increased in cases of subtotal resection and malignancy [9].

\section{Intraoperative complications}

There was only one case of intraoperative arrest (large convexity meningioma that was removed totally as (Simpson grade II) that was resuscitated and admitted to intensive care unit (ICU) and survived with postoperative hemiplegia that improved to hemiparesis (grade III power) within 6 months of follow-up and physiotherapy).

There was another intraoperative complication that occurred in this study group; the patient developed severe hypertension (220/110) during recovery from anesthesia with postoperative hematoma in the tumor 

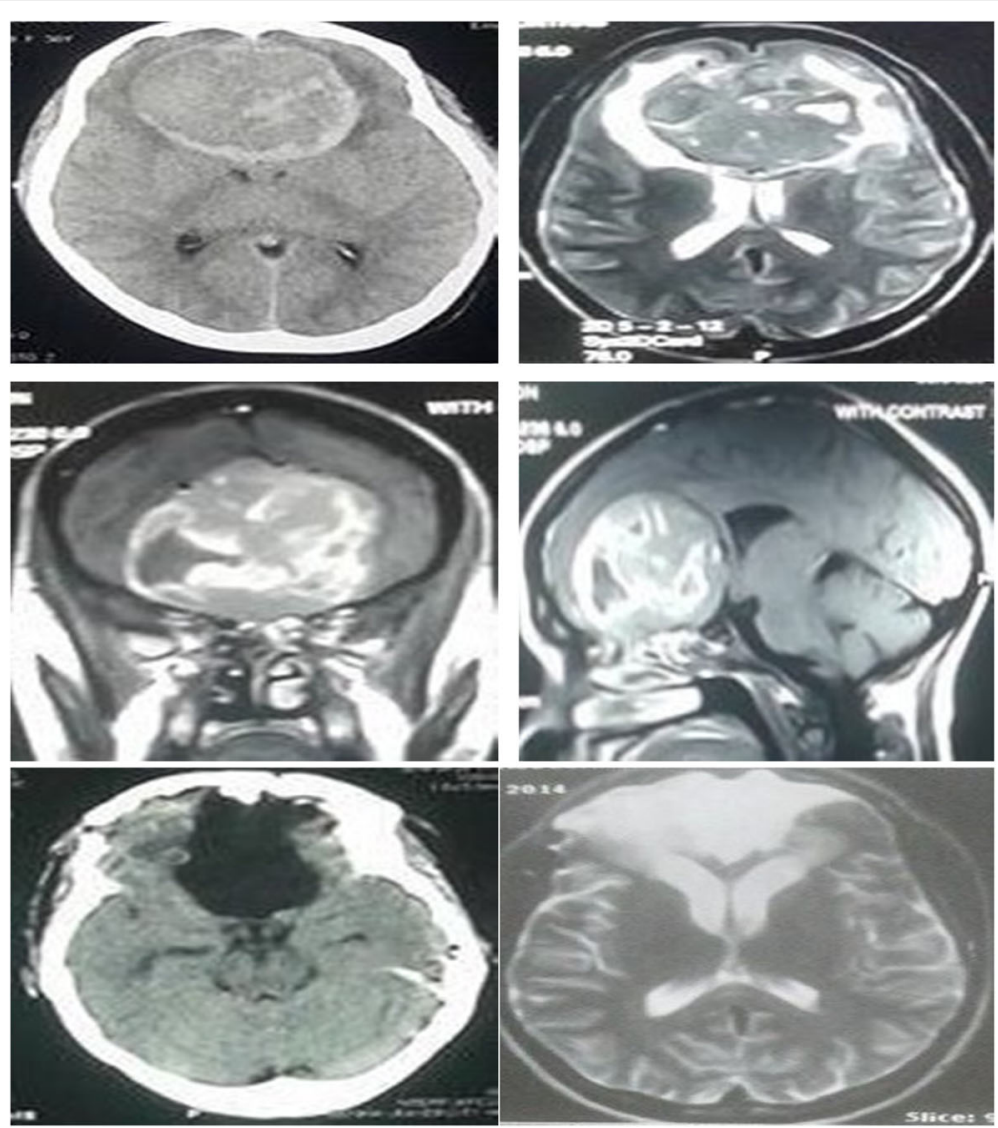

Fig. 1 Giant olfactory groove meningioma. Upper left, axial CT brain with contrast. Upper right, axial MRI TII of the same lesion with cystic components inside lesion. Middle left, coronal MRI with contrast showing heterogeneous enhancement. Middle right, sagittal MRI with contrast with heterogeneous enhancement. Lower left, postoperative CT 1 month later with bifrontal craniotomy and large cerebrospinal fluid (CSF) space in place of tumor removal after total removal. Lower right, MRI TII axial cut of the same case done 1 year after surgery with total removal and no recurrence

bed (pterional meningioma) that resolved within 3 weeks of follow-up with serial CT brain. The patient developed hemiparesis that was persistent during the follow-up period.

New cranial nerve deficit occurred in 14 cases (29\%); in 8 cases, the deficit was transient, and complete recovery has occurred within 3 months with return to normal status, but unfortunately, 6 cases (13\%) had sustained cranial nerve deficit (4 cases with new onset loss of olfaction, 1 case with moderate facial palsy, and 1case with trigeminal nerve affection).

\section{Complications}

Hemiparesis occurred in 3 cases (6\%), permanent cranial nerve deficit in 6 cases (13\%), and cerebrospinal fluid (CSF) leak in 7 cases (15\%) that has been resolved with conservative treatment (the leak stopped within 1 week in all cases) (Table 3). Conservative treatment was bed rest, antibiotics, and cidamex; however, we needed to do lumbar drain in two cases in the 2nd postoperative day due to excess leak; infection has occurred in 2 cases $(4 \%)$ in which antibiotic therapy gave good results. It was observed that the rate of complications is increased with increased patient age.

\section{Pathological results}

All cases were WHO GRADE I except for one case that was grade II.

\section{Mortality}

The mortality rate in this study was $4 \%$ ( 2 cases) with no cases of reported intraoperative mortality. One of them died suddenly more than 1 year after surgery; the other case had tumor recurrence within 2 years after surgery and refused to do another surgery, she was obese with associated comorbidities, 1 day (within 

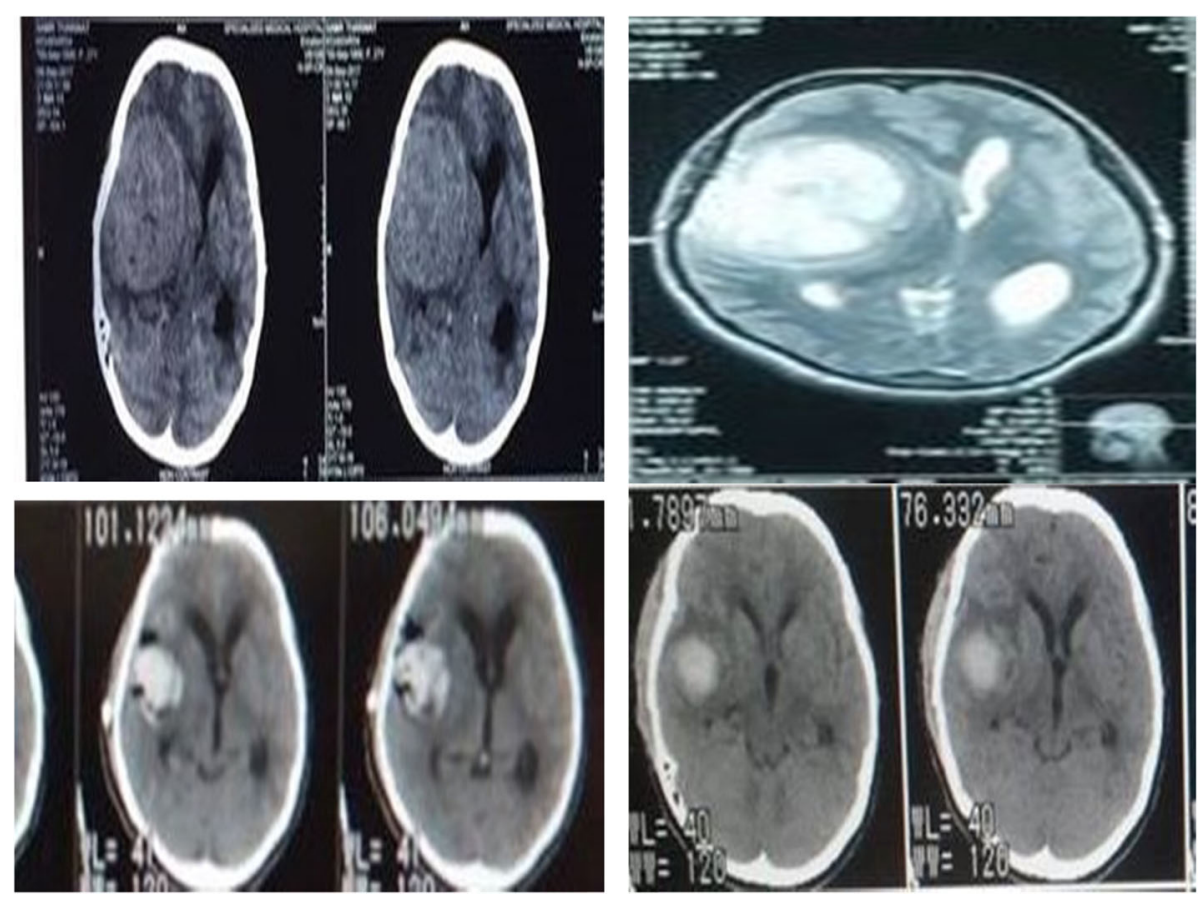

Fig. 2 Right-sided pterional giant meningioma. Upper left, axial CT brain without contrast show isointense meningioma with midline shift. Upper right, axial T2 MRI of the same lesion with midline shift. Lower left, early postoperative CT brain showing hematoma in the tumor bed. Lower right, 2 weeks later postoperative CT brain with resolution of hematoma
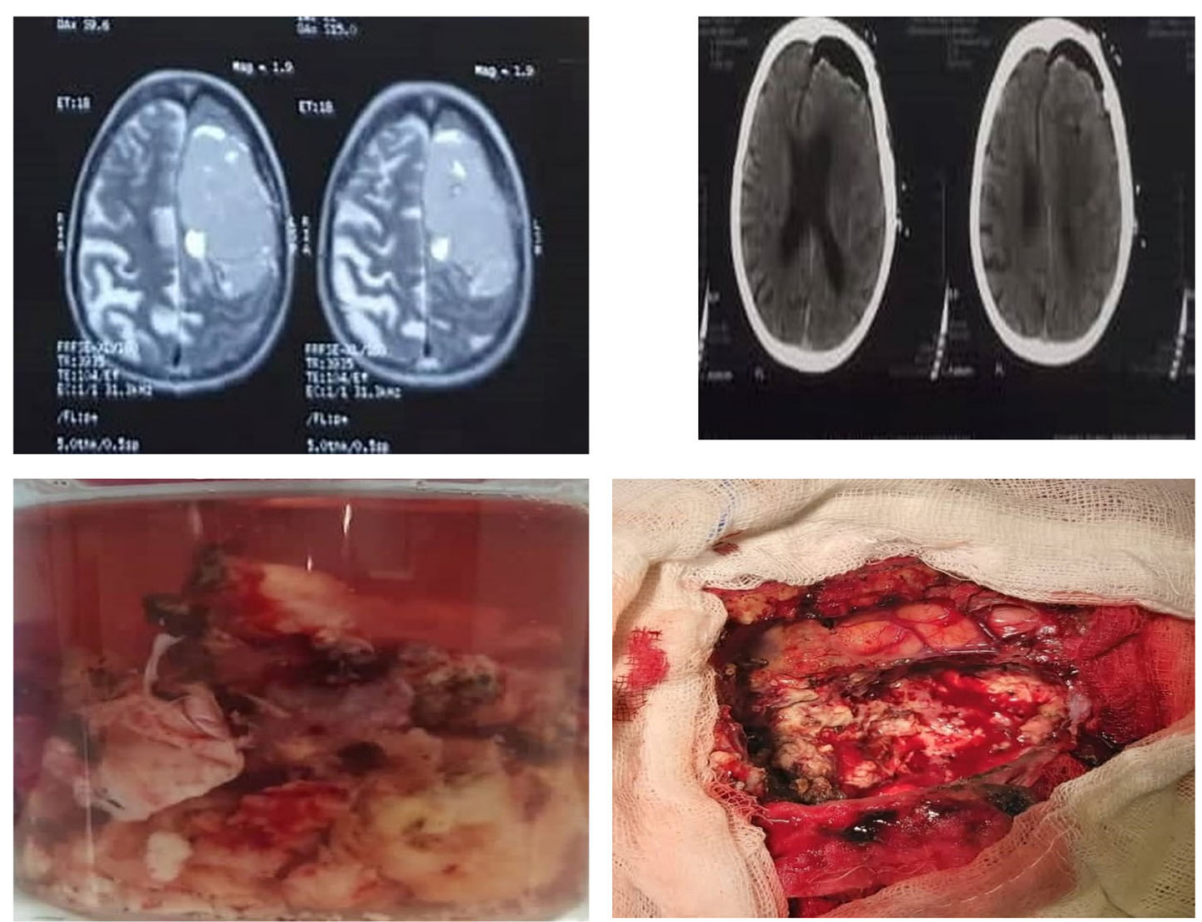

Fig. 3 Left frontoparietal giant convexity meningioma. Upper left, axial T2-weighted image showing the lesion which is hyperintense to the brain with minimal mass effect. Upper right image, 1 day postoperative CT brain follow-up showing complete removal of the lesion. Lower left, tumor pieces for histopathological analysis. Lower right, intraoperative view showing the tumor during resection and the tumor brain interface 

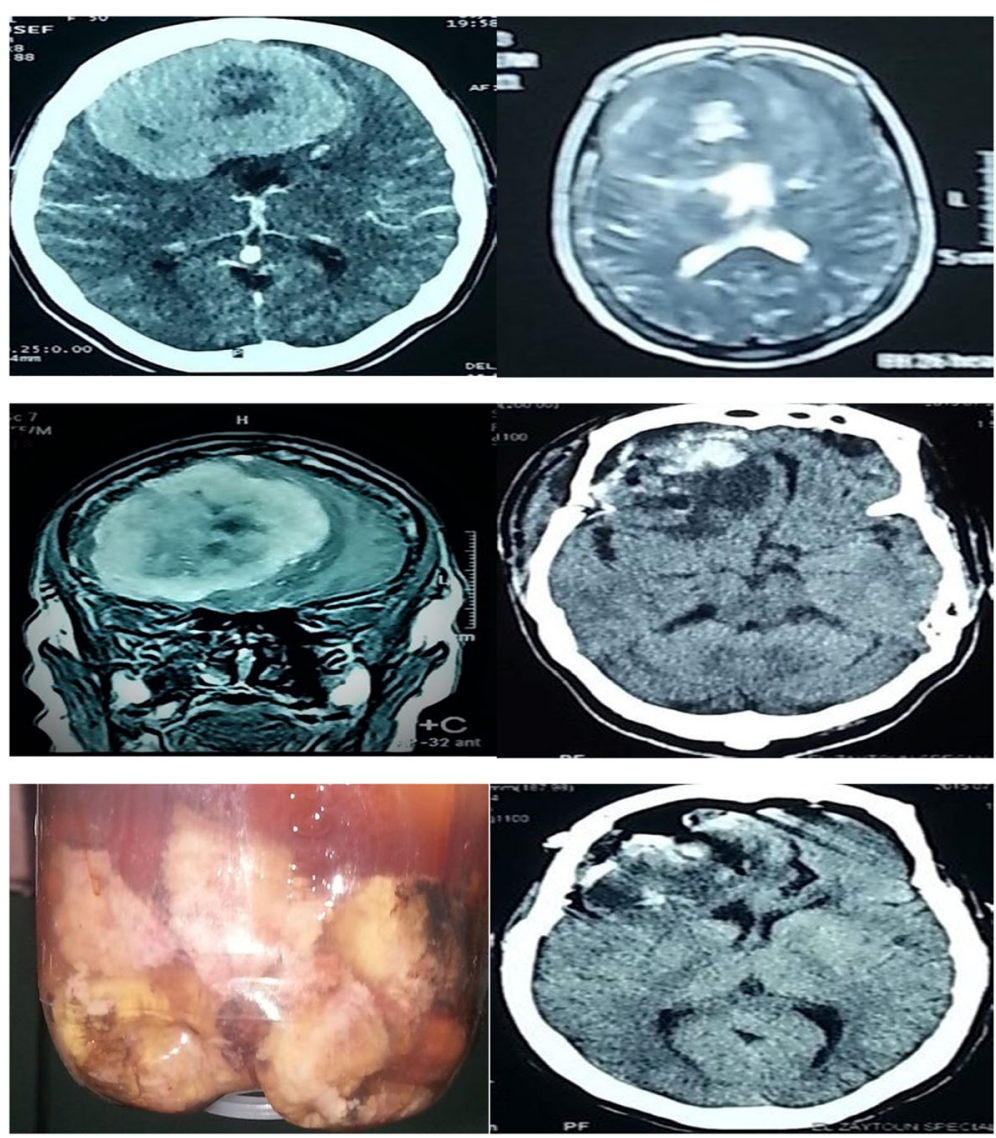

Fig. 4 Upper left, preoperative axial CT brain with contrast showing giant olfactory groove meningioma. Upper right, axial MRI T2-weighted image of the same patient. Middle left, coronal MRI with contrast of showing hyper intense lesion with heterogeneous contrast enhancement. Middle right, 1 day postoperative axial CT brain showing complete tumor removal with mild edema. Lower left, pieces of tumor after surgical removal. Lower right, 3 months postoperative CT brain after complete tumor removal

3 years) she developed dyspnea and cyanosis and was admitted to ICU and was diagnosed as pulmonary embolism (PE), unfortunately she died within 1 day of admission to the ICU.

\section{Discussion}

We performed a retrospective study on cases of intracranial giant meningiomas that have diameter larger than $6 \mathrm{~cm}$. Good understanding of preoperative status and evaluation, taking care of the risk factors, choice of the most suitable surgical approach, and meticulous use of intraoperative aiding devices are the most important factors with great value in GIM removal.

In a study performed by Narayan et al., they found that the most important factors that leads to good outcome includes younger males, intraoperative neuronavigation assistance, and skull base location, while the factors that lead to bad outcome were Simpson grade 3 or 4 and bad histologic grade. This study included 80 cases, 27 males (33.8\%) and 53 females $(66.3 \%)$ with a mean age of 56 years. This study included cases with tumor size less than $5 \mathrm{~cm}$ while in our study the minimum tumor size was more than $6 \mathrm{~cm}$. In this study, most cases were of skull base type, WHO grade I, and Simpson grade II excision was the most commonly achieved mode of surgical treatment with higher intraoperative mortality than our series ( $5 \%$ while it was $0 \%$ in our study) [5].

In a study performed by Da Silva and De Freitas, all cases were skull base meningiomas while in our study skull base tumors represent 67\% (32 cases). The differentiating diameter in this study was $4 \mathrm{~cm}$ while in our study it was larger $(6 \mathrm{~cm})$. Simpson grade I removal was performed in $45 \%$ of cases of this study while in our study it was $20 \%$ which is little than this study while grade II Simpson excision was performed in 55\% which is larger than that in this study (30\%). Recurrence rate in our study $(8 \%)$ 

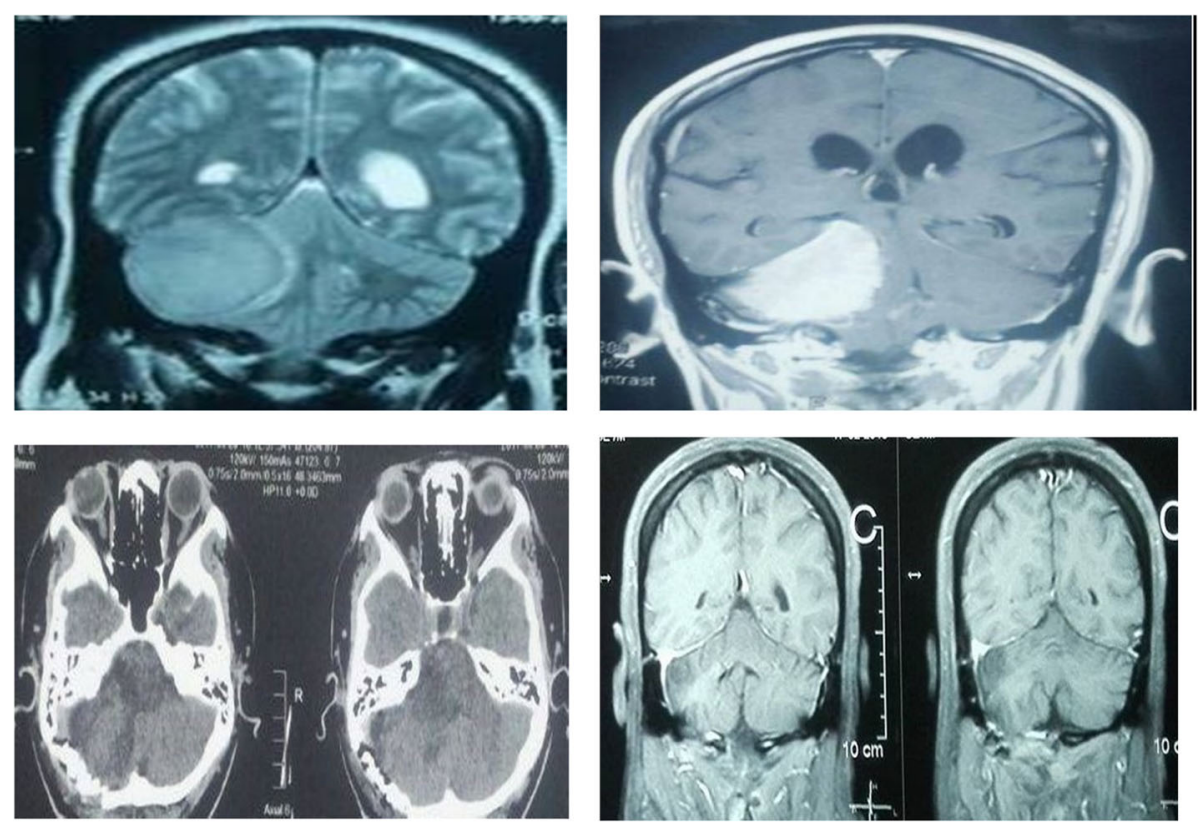

Fig. 5 Right petroclival meningioma removed by right retrosigmoid approach. Upper left, coronal TII MRI image showing giant lesion. Upper right, coronal MRI brain with contrast showing homogeneous contrast enhancement. Lower left, axial CT brain done 1 day postoperative showing total removal. Lower right, coronal MRI brain with contrast done 1 year after surgery showing total removal with no recurrence

was larger than that in this study (4\%) which may be related to more radical removal in this study (Simpson grade one was 45\%). Da Silva and de Freitas recommended total radical tumor removal to gain better results [6].

Tuna et al. performed a retrospective study including 93 patients. The cases were 31 men and 62 women; the mean age was $48.7 \pm 2.3$ years. All tumors in that series were larger than $6 \mathrm{~cm}$. In this series, total removal was performed in $63.4 \%$ of cases, and subtotal removal was performed in $35.5 \%$ with an overall mortality rate of $11.5 \%$. The results in our study were better ( $90 \%$ total tumor removal compared to $63.4 \%$ in this series), the mortality rate was less ( $4 \%$ in our series compared to $11.8 \%$ in this series), the overall recurrence rate was 19\% (compared to $8 \%$ in our series), and the most common location in this study was the parasagittal region in 18 patients (19.3\%), compared to our study the most common location was olfactory groove $(13$ cases $=27 \%)$ and convexity meningiomas (13 cases $=27 \%)$ [1].

In literature, few studies talk about giant meningioma; most studies include tumor diameter less than $5 \mathrm{~cm}$.

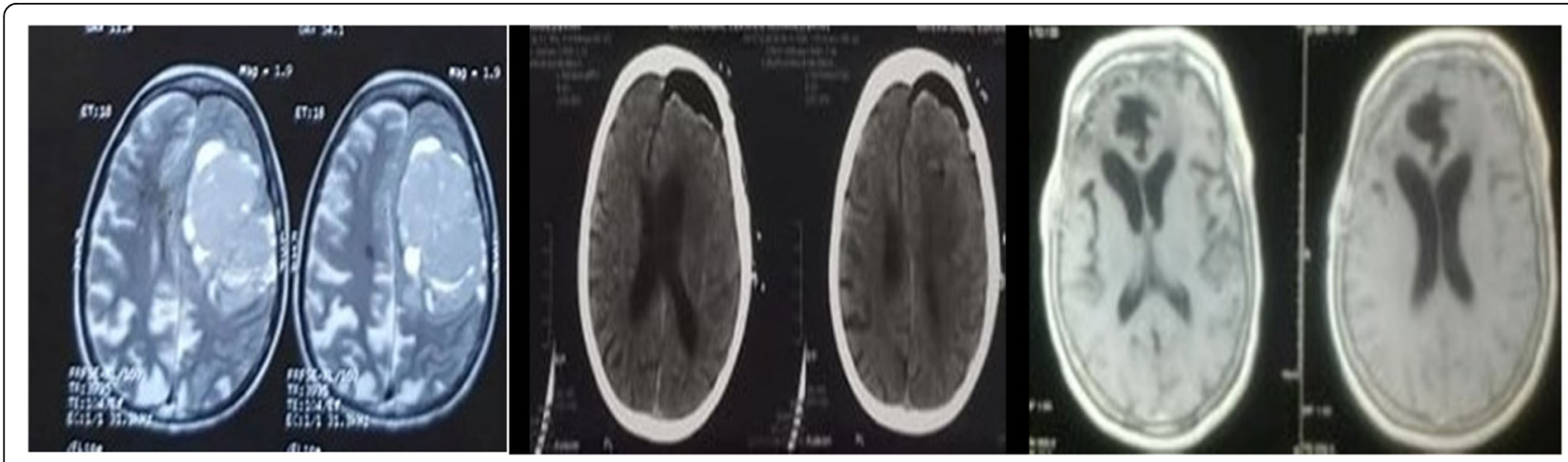

Fig. 6 Left convexity meningioma. Left, preoperative axial MRI TII. Middle, CT brain done in the 2nd postoperative day with no residual. Right image, axial MRI TI image done 2 years after surgery with no recurrence 
Table 1 Patient characteristics

\begin{tabular}{ll}
\hline Criteria & No. \\
\hline Gender & \\
M & $7(15 \%)$ \\
F & $41(85 \%)$ \\
Mean age & 49 \\
Previous surgery & $3(6 \%)$ \\
Follow-up period & 6 months-5 years(mean 36 months) \\
\hline
\end{tabular}

Radiosurgery is used mainly after subtotal removal of meningioma and after removal of atypical or malignant meningiomas [10-13]. In our series, postoperative radiosurgery was used in 5 cases that were removed subtotally (Simpson grade IV). The tumor size showed no enlargement in three cases while two cases showed progressive tumor enlargement. In a study performed by Goldsmith et al., the tumor control following postoperative radiosurgery was 89\% using a median dose of $45 \mathrm{~Gy}$ in 130 cases [14].

In a study performed by Hentshel and Demonte, the recurrence rate was $0 \%$ [15] while in our study the recurrence rate was $(8 \%)$; this may be due to few number of cases (13 cases), and all of them were olfactory groove meningioma, and some tumors were less than $6 \mathrm{~cm}$ in maximal diameter.

In our series, only one case was WHO grade II while all of the other cases were WHO grade I; in a series including 1113 case performed by Magill et al., 905 (81\%) cases were WHO grade I and 208 cases (19\%) had neoplasms WHO grade II [16].

\section{Conclusion}

Management of giant intracranial meningioma is a relatively common practice in neurosurgical centers in developing countries with the aim of radical total surgical removal being the first and most optimum option. Large size makes surgery difficult but young age, meticulous surgical techniques, proper localization, trying to minimize operative time, and Simpson grade are of special value. Interdisciplinary cooperation is essential to avoid the common complications like PE, postoperative hematoma in tumor bed that leads to bad surgical outcome.

Table 2 Results of surgery

\begin{tabular}{ll}
\hline Criteria & No. \\
\hline Gross total removal (GTR) & $90 \%$ \\
Postoperative radiosurgery & $5(10 \%)$ \\
Recurrence & $4(8 \%)$ \\
Mean time of FU & 36 months \\
\hline
\end{tabular}

Table 3 Complications

\begin{tabular}{ll}
\hline Criteria & No. \\
\hline Intraoperative & $2(4 \%)$ \\
Hemiparesis & $3(6 \%)$ \\
Cranial nerve deficit & $6(13 \%)$ \\
CSF leak & $7(15 \%)$ \\
Infection & $2(4 \%)$ \\
\hline
\end{tabular}

\section{Abbreviations}

COZ: Cranio-orbitozygomatic; CPA: Cerebellopontine angle; CSF: Cerebrospinal fluid; CT: Computerized tomography; CUSA: Cavitronic ultrasonic aspiration device; GIM: Giant intracranial meningioma; GTR: Gross total removal; ICU: Intensive care unit; MRA: Magnetic resonance angiography; MRI: Magnetic resonance imaging; PE: Pulmonary embolism; SRS: Stereotactic radiosurgery; WHO: World Health Organization

\section{Acknowledgements}

Not applicable.

\section{Authors' contributions}

Dr. Mohammed Emara operated on some cases and wrote the review. Dr. Ramy Teama operated on some cases and wrote "Patients and methods" section in addition to "Results" while Dr. Mohammed Adawi operated on some cases and wrote the "Discussion" and "Conclusion" sections. All authors read and approved the final manuscript.

\section{Funding}

Not applicable. No funding was used in this study.

\section{Availability of data and materials}

The databases used during the current study are available from the corresponding author on reasonable request.

\section{Ethics approval and consent to participate}

Research committee approval has been granted for this study by the Research Ethics Committee, Faculty of Medicine Benha University, with ethics committee approval number Rc.6.4.2020.

\section{Consent for publication}

Not applicable.

\section{Competing interests}

The authors declare that they have no competing interests.

Received: 15 March 2020 Accepted: 1 November 2020

Published online: 01 December 2020

\section{References}

1. Tuna M, Göçer I, Gezercan Y, et al. Huge meningiomas a review of 93 cases. World Neurosurg. 1998;60:55-63.

2. Claus EB, Bondy ML, Schildkraut JM, et al. Epidemiology of intracranial meningioma. Neurosurgery. 2005;57:1088-95.

3. Hou J, Kshettry $V$, Selman W, et al. Peritumoral brain edema in intracranial meningiomas: the emergence of vascular endothelial growth factordirected therapy. Neurosurg Focus. 2013;35:6.

4. Preston-Martin S. Epidemiology of primary CNS neoplasms. Neurol Clin. 1996;14:273-90.

5. Narayan V, Bir SC, Mohammed N, et al. Surgical management of giant intracranial meningioma: operative nuances, challenges, and outcome. World Neurosurg. 2018;110:32-41.

6. Da Silva CE, De Freitas PE. Large and giant skull base meningiomas: Tthe role of radical surgical removal. Surg Neurol Int. 2015;6:113-9.

7. Sun SQ, Cai C, Murphy RK, et al. Management of atypical cranial meningiomas, part 2: predictors of progression and the role of adjuvant radiation after subtotal resection. Neurosurgery. 2014;75:356-63.

8. Yashita J, Handa H, Jwaki K, et al. Recurrence of intracranial meningiomas, with special reference to radiotherapy. Surg Neurol. 1980;14:33-40. 
9. Mirimanof RO, Dosoretz DE, Lingood RM, et al. Meningioma: analysis of recurrence and progression following neurosurgical resection. J Neurosurg. 1985;62:18-24.

10. De Monte F. Current management of meningiomas. Oncology (Williston Park). 1995;9:83-91.

11. Rockhill J, Mrugala M, Chambelin M. Intracranial meningiomas: an overview of diagnosis and Treatment. Neurosurg Focus. 2007;23:4.

12. Sanson M, Cornu P. Biology of meningiomas. Acta Neurochir (Wein). 2000; 142:493-505.

13. Wilson CB. Meningiomas: genetics, malignancy, and the role of radiation in induction and treatment. The Richard C. Schneider Lecture. J Neurosurg. 1994;81:666-75.

14. Goldsmith BJ, Wara WM, Wilson CB, et al. Postoperative irradiation for subtotally resected meningiomas: Aa retrospective analysis of 140 patients treated from 1967 to 1990. J Neurosurg. 1994:80:195-201.

15. Hentshel S, Demonte F. Olfactory groove meningiomas. Neurosurg Focus. 2003;14:6.

16. Magill S, Young J, Manish R, et al. Relationship between tumor location, size, and WHO grade in meningioma. Neurosurg Focus. 2018;44:4.

\section{Publisher's Note}

Springer Nature remains neutral with regard to jurisdictional claims in published maps and institutional affiliations.

\section{Submit your manuscript to a SpringerOpen ${ }^{\circ}$ journal and benefit from:}

- Convenient online submission

- Rigorous peer review

- Open access: articles freely available online

High visibility within the field

- Retaining the copyright to your article

Submit your next manuscript at $\boldsymbol{\nabla}$ springeropen.com 